\title{
Interactive comment on "Fate of rice shoot and root residues, rhizodeposits, and microbe-assimilated carbon in paddy soil: I. Decomposition and priming effect" by Zhenke Zhu et al.
}

\section{Anonymous Referee \#1}

Received and published: 17 May 2016

General comments The manuscript submitted by Zhu et al. investigated the fate and priming effect of organic $C$ incorporated into paddy soils by plants and microorganisms through a long incubation study. The four different 13C-labelled substrates, i.e., rice roots, shoots, rhizodeposits and microbial assimilated carbon were used to analysis the mineralization processes. The topic is within the scope of this journal, and benefit for understanding the dynamics of $\mathrm{C}$ cycling and environmental protect in paddy soil ecosystem. They found that the mineralization of native soil organic matter was 2.6 and 2.0 fold higher in shoot- $\mathrm{C}$ and root- $\mathrm{C}$, and positive priming effects were found in the two $\mathrm{C}$ substrates. The rhizodeposits and microbial assimilated $\mathrm{C}$ showed no

Printer-friendly version

Discussion paper 
significant differences in the total amount of emitted carbon compared with control and the negative priming effects. The above results can give new insights for soil $\mathrm{C}$ turnover and biogeochemical cycling mechanisms. In summary, this is a strong and well-done manuscript that needs only minor revisions.

\section{Specific comments}

1. The incubation study used $13 \mathrm{C}$ labeled microbial assimilated $\mathrm{C}$ and rhizodeposited C. How to label them? Please give more details about this.

2. The study is a long incubation experiment. How to reduce the cross-feeding effect? Especially, all the rice shoots, roots, rhizodeposits can be assimilated into microbial biomass $\mathrm{C}$. Did the formulas already take into account the cross-feeding effects between different $\mathrm{C}$ substrates?

Interactive comment on Biogeosciences Discuss., doi:10.5194/bg-2016-86, 2016. 